\title{
African swine fever: an unprecedented disaster and challenge to China
}

\author{
Tao Wang, Yuan Sun and Hua-Ji Qiu*
}

\begin{abstract}
Background: African swine fever (ASF), caused by African swine fever virus, is a hemorrhagic and often fatal disease of domestic pigs and wild boar, which is notifiable to the World Organization for Animal Health. On August 3, 2018, China reported the first outbreak of ASF in Shenyang, a northeastern city of China. As of October 8, a total of 33 ASF outbreaks were reported in eight provinces in China, the biggest pork producer and consumer in the world.

Main body: This commentary summarizes the current situation of ASF in China, measures that China has taken to control the disease, lessons learnt from other countries, challenges and recommendations on ASF control in China, and possible international collaborations on ASF.

Conclusions: ASF is an unprecedented disaster and challenge to the Chinese swine industry. It will be a formidable and protracted campaign to control ASF in China, which requires joint participation and coordination of stakeholders and agencies at different levels.
\end{abstract}

Keywords: African swine fever, Control, China

\section{Multilingual abstracts}

Please see Additional file 1 for translations of the abstract into the five official working languages of the United Nations.

\section{Background}

On August 3, 2018, China reported an outbreak of African swine fever (ASF) in Shenyang, a northeastern city of China [1]. This is the first emergence of ASF in China, which is the largest pork producer and consumer in the world. As of October 8, a total of 33 ASF outbreaks have been reported in eight provinces in the country (Fig. 1; Table 1). Though the ASF viral sequence in China is highly homologous to that of the Georgia 2007/1 strain [2], it remains a mystery where and how the virus came from [3]. It is speculated that the disease might have been introduced from an ASF-affected Eastern European country via smuggled pork or offals.

ASF is a hemorrhagic and often fatal disease of domestic pigs and European wild boar, and is notifiable to the World Organization for Animal Health (OIE). The disease is caused by African swine fever virus (ASFV),

\footnotetext{
* Correspondence: qiuhuaji@caas.cn

State Key Laboratory of Veterinary Biotechnology, Harbin Veterinary Research Institute, Chinese Academy of Agricultural Sciences, Harbin 150069, China
}

which is the sole member of the genus Asfivirus within the family Asfaviridae. ASFV is a tick-borne large DNA virus with complex transmission cycles among pigs, wild boar and soft ticks, and encodes more than 150 viral proteins with half of unknown functions. The virus shows high genetic and antigenic diversity. Up to now, 24 genotypes and 8 serogroups have been identified globally $[4,5]$.

\section{What has China done up to now?}

The Ministry of Agriculture and Rural Affairs (MARA) of China has issued a number of policies and regulations for the prevention and control of ASF before and after ASF outbreaks in China (Table 2). Following confirmation of ASF outbreaks in China, standard measures have been implemented to control the disease, including culling all the pigs within $3 \mathrm{~km}$ of the epidemic area, harmlessly destroying all the infected pigs and animal disposals and contaminants. Till now, around 50000 infected and affected pigs in the 33 ASF outbreaks in China have been culled (data from OIE), and the infected farms and contaminated materials were cleaned and disinfected. Following confirmation of the first ASF outbreak in China, the MARA immediately reported this event to the OIE on the same day and launched the ASF Contingency Plan and Emergency 


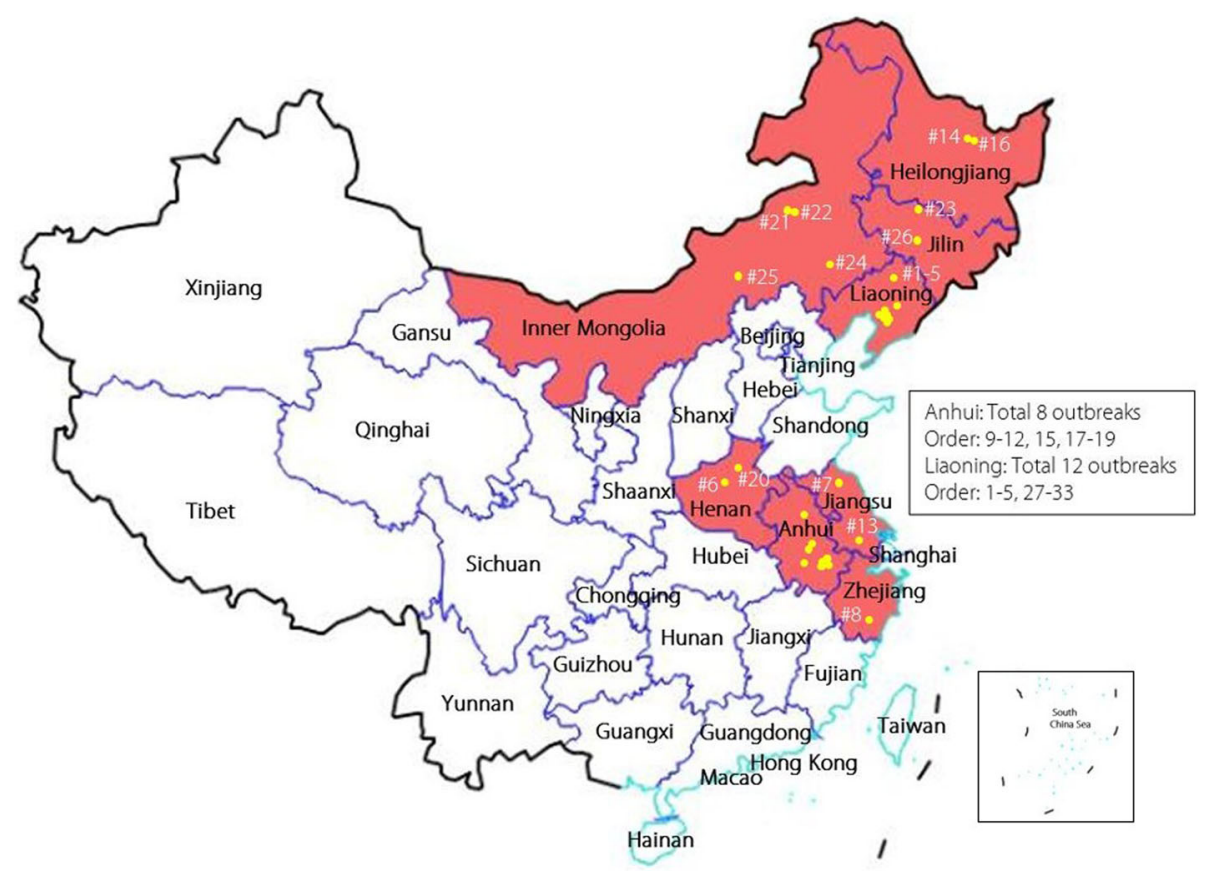

Fig. 1 African swine fever outbreak locations in China. The provinces with African swine fever outbreaks are shaded in red; numbers and dots indicate the order and locations

Response Level II. A series of regulations and actions have been taken by the MARA, including pig movement restriction inside the country, surveillance outside containment and/or protection zones, screening, quarantine, official destruction of pig products, official disposal of carcasses, by-products and wastes, stamping out, control of wildlife reservoirs, zoning, and disinfection, etc.

\section{Challenges for ASF control in China}

China has the largest swine population in the world, with 688.61 million pigs fattened in 2017, accounting for approximately $48 \%$ of the world's pork production (Source: Livestock and Poultry: World Markets and Trade, United States Department of Agriculture, April 2018). Meanwhile, small-scale and backyard farms with low biosecurity produce more than $60 \%$ pigs in China. A well-recognized high risk is swill-feeding currently practiced in many countries including China, which is a frequent route of ASFV introduction into ASF-free countries, e.g. Spain, The Netherlands, Belgium, Cuba, and Georgia [6]. A total of 20 ASF outbreaks occurred in farms mainly practicing swill-feeding in Anhui and Liaoning provinces of China. And illegal movement and slaughter of sick pigs before diagnosis pose another risk. The uneven distribution of the pig production in China makes long-distance pigs/pork transportation unavoidable, resulting in a higher risk of spreading ASF. Moreover, due to the endemic or epidemic situation of ASF in the Russian Federation and other countries, the disease has a high possibility to be reintroduced into China.

Another challenge is wild boar and soft ticks, which are natural hosts of ASFV and are widely distributed in China. We need to know if ASFV has taken root in wild boar and ticks after continuous outbreaks.

Though various vaccines against ASF are under development, none is commercially available. Difficulties in vaccine development need to be overcome, including safety concerns, poor cross-protection, and the lack of markers for sero-surveillance.

\section{Lessons learnt from other countries}

China can learn a lot of lessons from other countries with a history of ASF. Take Spain as an example. ASF was introduced into Spain in 1967 and was not well controlled until 1985 when the European Union provided sufficient financial support to eradicate the disease. Spain established a network of mobile veterinary team and a reference laboratory for ASF surveillance and outbreak identification. Animal movement was under strict control and illegal pork transportation was forbidden. Reasonable compensation was provided for culling pigs [7].

Russia is another mirror for China. ASF has spread widely and become an endemic disease in Russia since the first introduction in 2007. The main reasons are: (1) illegal movement of infected pigs and pork products, 
Table 1 Summary of African swine fever outbreaks in China

\begin{tabular}{|c|c|c|c|c|c|c|}
\hline Order & Date of confirmation & Locations (City, Province) & Susceptible & Cases & Deaths & Unit type \\
\hline$\overline{1}$ & Aug. 3, 2018 & Shenyang, Liaoning & 19420 & 47 & 47 & Farm \\
\hline 2 & Aug. 7, 2018 & Shenyang, Liaoning & 160 & 3 & 0 & Farm \\
\hline 3 & Aug. 7, 2018 & Shenyang, Liaoning & 55 & 1 & 0 & Farm \\
\hline 4 & Aug. 7, 2018 & Shenyang, Liaoning & 216 & 2 & 0 & Farm \\
\hline 5 & Aug.7, 2018 & Shenyang, Liaoning & 140 & 1 & 0 & Farm \\
\hline 6 & Aug. 16, 2018 & Zhengzhou, Henan & 1806 & 30 & 30 & Slaughterhouse \\
\hline 7 & Aug. 19, 2018 & Lianyungang, Jiangsu & 14686 & 615 & 88 & Farm \\
\hline 8 & Aug. 22, 2018 & Wenzhou, Zhejiang & 1864 & 430 & 340 & Farm \\
\hline 9 & Aug. 30, 2018 & Wuhu, Anhui & 459 & 185 & 80 & Farm \\
\hline 10 & Sept. 2, 2018 & Xuancheng, Anhui & 285 & 63 & 42 & Farm \\
\hline 11 & Sept. 2, 2018 & Xuancheng, Anhui & 440 & 153 & 111 & Farm \\
\hline 12 & Sept. 3, 2018 & Xuancheng, Anhui & 308 & 152 & 83 & Farm \\
\hline 13 & Sept. 3, 2018 & Wuxi, Jiangsu & 97 & 12 & 9 & Farm \\
\hline 14 & Sept. 5, 2018 & Jiamusi, Heilongjiang & 87 & 39 & 12 & Backyard \\
\hline 15 & Sept. 6, 2018 & Chuzhou, Anhui & 886 & 62 & 22 & Farm \\
\hline 16 & Sept. 6, 2018 & Jiamusi, Heilongjiang & 203 & 26 & 10 & Farm \\
\hline 17 & Sept. 6, 2018 & Wuhu, Anhui & 30 & 13 & 4 & Farm \\
\hline 18 & Sept. 6, 2018 & Xuancheng, Anhui & 52 & 15 & 15 & Farm \\
\hline 19 & Sept. 10, 2018 & Tongling, Anhui & 219 & 63 & 23 & Farm \\
\hline 20 & Sept. 14, 2018 & Xinxiang, Henan & 2087 & 148 & 64 & Farm \\
\hline 21 & Sept. 14, 2018 & XilinGol League, Inner Mongolia & 237 & 16 & 16 & Backyard \\
\hline 22 & Sept. 17, 2018 & XilinGol League, Inner Mongolia & 159 & 14 & 8 & Backyard \\
\hline 23 & Sept. 21, 2018 & Gongzhuling, Jilin & 484 & 56 & 56 & Farm \\
\hline 24 & Sept. 21, 2018 & Hinggan League, Inner Mongolia & 138 & 23 & 22 & Backyard \\
\hline 25 & Sept. 24, 2018 & Hohhot, Inner Mongolia & 388 & 4 & 2 & Slaughterhouse \\
\hline 26 & Sept. 28, 2018 & Songyuan, Jilin & 44 & 8 & 3 & Farm \\
\hline 27 & Sept. 30, 2018 & Yingkou, Liaoning & 130 & 22 & 22 & Village \\
\hline 28 & Sept. 30, 2018 & Yingkou, Liaoning & 9 & 2 & 2 & Village \\
\hline 29 & Sept. 30, 2018 & Yingkou, Liaoning & 239 & 78 & 78 & Village \\
\hline 30 & Oct. 7, 2018 & Yingkou, Liaoning & 1337 & 65 & 20 & Village \\
\hline 31 & Oct. 7, 2018 & Yingkou, Liaoning & 2608 & 127 & 27 & Village \\
\hline 32 & Oct. 7, 2018 & Yingkou, Liaoning & 9382 & 142 & 46 & Village \\
\hline 33 & Oct. 8, 2018 & Anshan, Liaoning & 909 & 160 & 160 & Farm \\
\hline
\end{tabular}

All Information of ASF outbreaks in China was retrieved through the World Organization for Animal Health Report and the Ministry of Agriculture and Rural Affairs of China

swill-feeding, and improperly handling infected pigs; (2) circulation of ASFV in wild boar and anthropogenic factors; (3) lack of effective prevention and control measures and nationally funded eradication program; (4) absence of veterinary oversight for the large number of small holdings and backyard pig farms with low biosecurity $[8,9]$.

\section{Recommendations on ASF control in China}

ASF is mainly transmitted by direct contact with infected pigs or ingestion of ASFV-contaminated pork products, etc. ASFV infection can also take place when the susceptible animals get physically in contact with ASFV. At present, no effective vaccines are commercially available and its control mainly relies on early detection and rapid eradication [10]. All the responsible stakeholders, including backyard farms, pig transporters, slaughter houses, veterinary services and authorities should join together to successfully implement the ASF control strategies. Effective measures must be adopted to control the disease.

To the Chinese government, with focus on coordination of surveillance and response activities: 
Table 2 Regulations issued by the Ministry of Agriculture and Rural Affairs of China for the prevention and control of African swine fever

\begin{tabular}{|c|c|c|c|}
\hline$\overline{\text { No. }}$ & Dates & Regulations & Sources \\
\hline$\overline{1}$ & Sept. 13, 2018 & $\begin{array}{l}\text { To stop using pig's blood products as raw materials to produce pig feed. } \\
\text { It is not allowed to feed pigs with untreated swills }\end{array}$ & MARA (Notice No. 64) \\
\hline 2 & Sept. 11, 2018 & $\begin{array}{l}\text { To prohibit interprovincial transportation of pigs and related products } \\
\text { from ASFV-affected provinces }\end{array}$ & MARA (No. 2018-33) \\
\hline 3 & Aug. 10, 2018 & To strengthen the supervision of pig transportation & MARA (No. 2018-38) \\
\hline 4 & Aug. 3, 2018 & To launch the ASF Contingency Plan and Emergency Response Level II & Information Office of MARA \\
\hline 5 & May 7, 2018 & $\begin{array}{l}\text { To prohibit importing pigs, wild boar and related products directly or } \\
\text { indirectly from Hungary. }\end{array}$ & MARA (Notice No. 35) \\
\hline 6 & Feb. 14, 2018 & About the prevention of ASF & MARA \\
\hline 7 & Dec. 3, 2017 & $\begin{array}{l}\text { About the Implementation of Technical Specifications for Prevention and } \\
\text { Control ASF (for trial implementation) }\end{array}$ & $\mathrm{MOA}$ \\
\hline 8 & Oct. 20, 2017 & About the implementation of ASF Emergency Plan & $\mathrm{MOA}$ \\
\hline 9 & Apr. 14, 2017 & Deployment to further strengthen risk prevention of ASF & MOA \\
\hline 10 & Mar. 20, 2017 & To strengthen the surveillance and epidemiological survey of ASF & MOA \\
\hline 11 & Sept. 3, 2007 & $\begin{array}{l}\text { To prohibit to import pigs, wild boar and related products directly or } \\
\text { indirectly from Armenia }\end{array}$ & MOA and AQSIQ (Notice No. 906) \\
\hline 12 & Aug. 8, 2007 & $\begin{array}{l}\text { To prohibit to import pigs, wild boar and related products directly or } \\
\text { indirectly from Georgia }\end{array}$ & MOA and AQSIQ (Notice No. 886) \\
\hline
\end{tabular}

MARA Ministry of Agriculture and Rural Affairs, formerly Ministry of Agriculture (MOA), AQSIQ Administration of Quality Supervision, Inspection and Quarantine

- Establishing a multi-sectoral linkage mechanism, coordinating different departments to prevent and control ASF;

- Establishing multi-line barriers and defenses;

- Establishing a real-time monitoring, traceable pig/ pork transportation system in line with biosecurity regulations; establishing inspection, quarantine and disinfection stations to control the movement of animal transportation vehicles from epidemic areas;

- Establishing a comprehensive surveillance and screen program and early test/reporting/warning and response system nationwide;

- Excluding small pig holders around the breeding units;

- Monitoring wild boar and ticks;

- Establishing a complete control system and strong technical support for disease prevention and control in epidemic, threatened and surrounding areas;

- Developing diagnostic assays for specific and early detection of suspected cases;

- Implementing a reasonable compensation policy;

- Owners of pig farms obligatorily to report any suspicious cases, ill or dead pigs to local veterinary authorities.

To pig owners, with focus on improving farm biosecurity measures:

- No introduction of pigs or semen from ASF-affected regions;
- Avoid carrying pork or related products from the outside to the farm;

- No addition of protein products of porcine origin in feed;

- No entry of visitors from ASF-epidemic regions;

- Clean and disinfect the trucks before and after pig transportation;

- Quarantine personnel for 1 to 3 days after traveling;

- Kill soft ticks, flies, and mosquitos.

\section{International collaborations on ASF}

ASF is a formidable transboundary disease. Since the ever-increasing personnel exchange and globalization, ASF has a high risk to be introduced into any ASF-free countries, especially Asian countries. Therefore, the battle against ASF needs the international participation.

A safe and effective vaccine is a priority for the cost-effective control of ASF in countries with a large swine population. Joint efforts on vaccine development should be made among international laboratories, including identification of virulence- and protection-associated proteins, generation and comprehensive evaluation of gene-deleted vaccine candidates with complete as well as cross-genotype protection, serological markers and no side-effects, and development of immunological parameters and assays for vaccine evaluation, etc.

Other activities include transboundary and inter-regional surveillance of ASF, information sharing, and training of young scientists, especially epidemiologists. 


\section{Conclusions}

ASF is a highly devastating swine disease. Undoubtedly, the emergence and spread of ASF in China, the largest pork producer in the world, is an unprecedented disaster. To control ASF in China, where there are a large number of small holders and frequent pig/pork transportation, is a challenging and long-lasting battle that needs the joint participation and coordination of all stakeholders nationally and internationally.

\section{Additional file}

Additional file 1: Multilingual abstracts in the five official working languages of the United Nations. (PDF $697 \mathrm{~kb}$ )

\section{Abbreviations}

ASF: African swine fever; ASFV: African swine fever virus; MARA: Ministry of Agriculture and Rural Affairs; OlE: World Organization for Animal Health

\section{Acknowledgements}

We thank Dr. Lihong Liu, National Veterinary Institute (SVA), Uppsala, Sweden, and Drs. Teshale Teklue and Yuzi Luo for revision of the manuscript.

\section{Funding}

This work was supported by the National Key Research and Development Program of China (No. 2017YFD0500601).

\section{Availability of data and materials}

Not applicable.

\section{Authors' contributions}

Tao Wang and Yuan Sun wrote the manuscript. Hua-Ji Qiu conceived and revised the manuscript. All authors read and approved the final manuscript.

\section{Ethics approval and consent to participate}

Not applicable.

\section{Consent for publication}

Not applicable.

\section{Competing interests}

The authors declare that they have no competing interests.

Received: 25 September 2018 Accepted: 18 October 2018

Published online: 26 October 2018

\section{References}

1. Zhou X, Li N, Luo Y, Liu Y, Miao F, Chen T, et al. Emergence of African swine fever in China, 2018. Transbound Emerg Dis. 2018. https://doi.org/10.1111/ tbed.12989.

2. Ge S, Li J, Fan X, Liu F, Li L, Wang Q, et al. Molecular characterization of African swine fever virus, China, 2018. Emerg Infect Dis. 2018;24(11):2131.

3. Li X, Tian K. African swine fever in China. Vet Rec. 2018;183(9):300-1.

4. Quembo CI, Jori F, Vosloo W. Heath L. Genetic characterization of African swine fever virus isolates from soft ticks at the wildlife/domestic interface in Mozambique and identification of a novel genotype. Transbound Emerg Dis. 2018;65:420-31.

5. Malogolovkin A, Burmakina G, Titov I, Sereda A, Gogin A, Baryshnikova E, et al. Comparative analysis of African swine fever virus genotypes and serogroups. Emerg Infect Dis. 2015;21:312-5.

6. Vergne T, Chen-Fu C, Li S, Cappelle J, Edwards J, Martin V, et al. Pig empire under infectious threat: risk of African swine fever introduction into the People's Republic of China. Vet Rec. 2017:181(5):117.

7. Arias M, Sanchez-Vizcaino JM. African swine fever eradication: the Spanish model. In: Morilla A, Jin K, Zimmerman J, editors. Trends in emerging viral infections of swine. Ames: lowa State University Press; 2002. p. 133-9.
8. Oganesyan AS, Petrova ON, Korennoy Fl, Bardina NS, Gogin AE, Dudnikov SA. African swine fever in the Russian Federation: spatio-temporal analysis and epidemiological overview. Virus Res. 2013;173(1):204-11.

9. Gogin A, Gerasimov V, Malogolovkin A, Kolbasov D. African swine fever in the North Caucasus region and the Russian Federation in years 2007-2012. Virus Res. 2013;173:198-203.

10. Bellini S, Rutili D, Guberti V. Preventive measures aimed at minimizing the risk of African swine fever virus spread in pig farming systems. Acta Vet Scand. 2016:58(1):82-91.

\section{Ready to submit your research? Choose BMC and benefit from:}

- fast, convenient online submission

- thorough peer review by experienced researchers in your field

- rapid publication on acceptance

- support for research data, including large and complex data types

- gold Open Access which fosters wider collaboration and increased citations

- maximum visibility for your research: over $100 \mathrm{M}$ website views per year

At BMC, research is always in progress.

Learn more biomedcentral.com/submission 